CLINICAL STUDY

\title{
Mortality from thyroid cancer in patients with hyperthyroidism: the Theagenion Cancer Hospital experience
}

\author{
Kalliopi Pazaitou-Panayiotou, Petros Perros ${ }^{1}$, Maria Boudina, George Siardos, Apostolos Drimonitis, \\ Frideriki Patakiouta ${ }^{2}$ and Iraklis Vainas \\ Department of Endocrinology-Endocrine Oncology, Theagenion Cancer Hospital, 2, Alexandrou Simeonidi Street, 54007 Thessaloniki, Greece, \\ ${ }^{1}$ Department of Endocrinology, Freeman Hospital, Newcastle upon Tyne, UK and ${ }^{2}$ Department of Pathology, Theagenion Cancer Hospital, 2, Alexandrou \\ Simeonidi Street, 54007 Thessaloniki, Greece \\ (Correspondence should be addressed to K Pazaitou-Panayiotou; Email: kpazaitou@in.gr)
}

\begin{abstract}
Background: Thyroid carcinoma has been reported in patients operated for different types of hyperthyroidism and the probability of a hot nodule being malignant seems to be low. The aim of the present study was to explore the relationship between thyroid cancer, hyperthyroidism and outcome in a large cohort of patients who presented to a tertiary cancer centre in Northern Greece.

Patients: Among 720 patients treated for thyroid cancer, 60 had a concomitant diagnosis of hyperthyroidism due to Graves' disease $(n=14)$, solitary autonomous adenoma $(n=17)$, or multinodular goiter $(n=29)$. Adverse prognostic factors were common in patients with a previous history of hyperthyroidism at the time of diagnosis of thyroid cancer, including cases where the cancer was discovered coincidentally after thyroid surgery for hyperthyroidism and cases where tumor size was more than $10 \mathrm{~mm}$.

Results: In 10 out of 17 patients with hyperthyroidism due to solitary autonomous adenomas, the tumor was located within the hot nodule and two of these patients developed local and distant metastases and died from the disease 4 and 15 years after thyroidectomy.

Conclusion: Clinicians managing patients with hyperthyroidism need to be aware of the possible increased risk of thyroid cancer in this patient group.

European Journal of Endocrinology 159 799-803
\end{abstract}

\section{Introduction}

The coexistence of thyroid cancer and hyperthyroidism in patients presenting with the latter is well described, although the nature of this relationship is controversial $(1,2)$. The reported incidence of thyroid cancer found at surgery for hyperthyroidism ranges from 0.21 to $9.0 \%$ $(1,3,4)$. The incidence of thyroid cancer may be increased in patients with Graves' disease presenting with a palpable nodule (5), while the probability of a hot nodule being malignant is low, ranging from 1 to $6 \%$ (6-8), but may be as high as $11 \%$ in children (9). Occasionally, some advanced thyroid cancers can cause hyperthyroidism due to autonomously functioning metastases $(10,11)$. Conversely, a history of hyperthyroidism in thyroid cancer patients is reported as 2.3$19 \%(8,12-16)$.

Some studies suggest that thyroid cancer is not only commoner than expected in patients with Graves' disease, but may also be more aggressive (8, 17-19), although these findings are not universal $(20,21)$. The published data on thyroid cancer in autonomously functioning nodules (solitary or within multinodular goiters), are scanty and mostly anecdotal.
The aim of the present study was to explore the relationship between thyroid cancer, hyperthyroidism, and outcome in a large cohort of patients who presented to a thyroid cancer centre.

\section{Patients and methods}

The case records of patients treated for thyroid cancer at Theagenion Cancer Hospital between 1988 and 2005 were reviewed. Patients with a diagnosis of both thyroid cancer and hyperthyroidism were identified and their characteristics were further analyzed. Hyperthyroidism was diagnosed on the basis of a low serum TSH ( $\mathrm{TSH}=0.094 \pm 0.090$, minimum 0.03 and maximum $0.3 \mathrm{U} / \mathrm{l}$, normal range $0.3-4.0 \mathrm{mU} / \mathrm{l})$, elevated thyroid hormone concentrations $(\mathrm{FT} 4=34.8 \pm 3.39$ normal range $9-26 \mathrm{pmol} / \mathrm{l}, \mathrm{FT} 3=9.25 \pm 1.46$, normal range 3-8 pmol/l) and concordant clinical features. Hyperthyroidism was classified according to the underlying etiology as solitary autonomous adenoma $(n=17)$, Graves' disease $(n=14)$, and multinodular goiter $(n=29)$. The diagnosis of Graves' disease was based on clinical features of ophthalmopathy and/or positive thyrotropin receptor 
antibodies. All patients with solitary autonomous adenoma had ${ }^{99}$ Tc-pertechnetate and ${ }^{131}$ I scans, which showed a hot area corresponding to the nodule with lower or no uptake in the remaining thyroid tissue. The diagnosis of multinodular goiter was based on clinical features, scintigraphy, and ultrasonography. Staging was assigned in accordance with the 5th edition of the TNM classification (22). All patients had the diagnosis of hyperthyroidism established 1-6 years (median 3.5 years) before the diagnosis of thyroid cancer and 55 of them received antithyroid drugs for the same period of time for the treatment of thyrotoxicosis. Five patients (three with autonomous adenoma and two with toxic multinodular goiter), received only $\beta$ blockers as the hyperthyroidism was deemed to be mild.

\section{Pathology}

All thyroid tissue samples were oriented, cut in parallel longitudinal slices each $5 \mathrm{~mm}$ thick and fixed in 10\% neutral buffered formalin for $24 \mathrm{~h}$. After fixation the samples were finely cut and paraffin embedded. For solitary encapsulated nodules measuring up to $5 \mathrm{~cm}$, an additional section was taken for each additional centimeter in diameter, including the tumor capsule and adjacent thyroid tissue. For multinodular goiters, one section of each nodule (up to five nodules) was taken and more than one section for larger nodules (23). Samples were routinely processed after paraffin embedding. Normal tissue adjacent to neoplastic areas was also evaluated. All samples were retrospectively examined by one pathologist (FP). Pathologists were consistent in looking for coincidental microcarcinomas.

\section{Statistical analysis}

Summary statistics for continuous variables were expressed as mean \pm s.D. Cross-tabulation and Pearson's chi-square test, as well as one-way ANOVA were used for examining the relationship between two categorical variables, as tests of independence and measures of association. Variables analyzed were age, sex, tumor size, number of tumor foci, lymph node metastases and invasion of thyroid parenchyma, thyroid capsule, extrathyroidal invasion, or vessels invasion. A second data analysis was done with the same parameters excluding microcarcinomas. Calculations were carried out using SPSS version 12.0. Results were considered statistically significant when $p$ value was less than 0.05 .

\section{Results}

Between 1988 and 2005, 720 consecutive patients with thyroid cancer were treated at Theagenion Cancer Hospital, a tertiary referral center for patients with thyroid cancer in Northern Greece. Review of the case records identified 60 patients with a previous diagnosis of hyperthyroidism and thyroid cancer, who comprised the study group. Their clinical characteristics are shown in Table 1. None of the patients had received previous radioiodine treatment or external beam irradiation. The indication for surgery was suspicion of thyroid cancer in 12 patients (cervical lymphadenopathy with positive fine-needle aspiration cytology (FNAC) in two patients with Graves' disease and two with solitary autonomous adenoma, positive FNAC of a clinically suspicious nodule in three patients with toxic multinodular goiter and one cold nodule in a patient with Graves' disease, and suspicious ultrasonographic findings in three patients with multinodular goiter and one with Graves' disease). In the remaining 48 patients the indication for thyroidectomy was treatment for thyrotoxicosis. Among this group of thyrotoxic patients with no preoperative suspicion of thyroid cancer, a surprisingly high proportion $17 / 48(35.40 \%)$ had advanced disease, including $11 / 48$ (22.9\%) with extrathyroidal soft tissue invasion. No significant correlations were found between type of hyperthyroidism, sex or age, and disease stage at diagnosis. All patients with preoperative suspicion or diagnosis of thyroid cancer had stage II-IVA disease. There were no significant differences in clinical characteristics at presentation between coincidentally discovered thyroid cancers and those with preoperative suspicion or diagnosis of thyroid cancer.

All but 5 out of the 60 patients had total/near total or completion thyroidectomy. The remaining five patients had lobectomies/subtotal thyroidectomies (all of these cases had tumors less than $1 \mathrm{~cm}$, without evidence of residual disease). Ablation therapy with $100 \mathrm{mCi}$ of ${ }^{131} \mathrm{I}$ was administered in 35/57 patients with follicular cell thyroid cancers. Patients with unifocal microcarcinoma without lymph nodes metastases or extrathyroid invasion were not ablated (24). All patients received levothyroxine therapy in a dose of $1.5-2 \mu \mathrm{g} / \mathrm{kg}$ per day after surgery $/ 131 \mathrm{I}$ ablation aiming to suppress the serum TSH to less than $0.1 \mathrm{mU} / \mathrm{l}$.

Table 1 Clinical characteristics of patients with hyperthyroidism and thyroid cancer.

\begin{tabular}{|c|c|c|}
\hline & $\begin{array}{l}\text { Carcinomas } \\
\leq 10 \mathrm{~mm}\end{array}$ & $\begin{array}{l}\text { Carcinomas } \\
>10 \mathrm{~mm}^{\mathrm{a}}\end{array}$ \\
\hline$n$ & 39 & 21 \\
\hline Male/female & $3 / 36$ & $8 / 13$ \\
\hline $\begin{array}{l}\text { Mean age at the diagnosis } \\
\text { of cancer }\end{array}$ & $50.36 \pm 13.81$ & $51.62 \pm 14.45$ \\
\hline $\begin{array}{l}\text { Time from diagnosis of } \\
\text { hyperthyroidism to } \\
\text { thyroidectomy (median) }\end{array}$ & $\begin{array}{l}3.5 \text { years } \\
\quad \text { (range 1-6) }\end{array}$ & $\begin{array}{l}3.3 \text { years } \\
\quad \text { (range 1-6) }\end{array}$ \\
\hline $\begin{array}{l}\text { Carcinomas located within } \\
\text { hot nodules }\end{array}$ & $4 / 10$ & $6 / 10$ \\
\hline
\end{tabular}

${ }^{a}$ No significant difference was found between the mean age of the patients and tumor size. 


\section{Pathology}

Three medullary and 57 differentiated thyroid cancers were identified. The size of tumors was $1-10 \mathrm{~mm}$ in 39 (65\%) and more than $10 \mathrm{~mm}$ in 21 patients (Table 2$)$. The proportion of microcarcinomas (tumor size $\leq 10 \mathrm{~mm}$ ) in the different types of hyperthyroidism were: $64.7 \%$ in patients with solitary autonomous adenomas, 50.0\% in patients with Graves' disease, and $72.4 \%$ in patients with toxic multinodular goiter. These differences were not significant $\left(x^{2}=2.086, P=0.36\right)$. No correlation was found between tumor size and age of the patient $(t=-0.332, P=0.7$; Table 1$)$. Seven out of 39 patients with tumor $\leq 10 \mathrm{~mm}$ in diameter displayed features of aggressive behavior: two patients had lymph nodes metastases, in two patients there was tumor invasion of thyroid parenchyma, and in three patients there was extrathyroidal extension. In 18/39 patients with microcarcinomas multiple tumor foci were present and in 14/39 patients the tumor had the characteristics of the so-called 'occult papillary thyroid carcinoma'. In 10 out of the 17 (58.79\%) patients with solitary autonomous adenomas, the tumor was located within the hot nodule (in seven, the entire nodule was malignant with tumor size more than $10 \mathrm{~mm}$ in 6 and $10 \mathrm{~mm}$ in one patient, and in three there was an area of microcarcinoma within the nodule) and was of papillary type in eight cases and follicular in two. In the other seven patients with solitary autonomous adenomas, a microcarcinoma was located outside the hot nodule and was papillary in all cases (one follicular variant, one tall cell variant). No correlation was found between tumor size, number of tumor foci, or invasion in different forms of hyperthyroidism. There was a trend for a higher prevalence of lymph node metastases at the time of diagnosis of thyroid cancer in patients with Graves' disease and autonomous adenoma than in patients with multinodular goiter $(P=0.05)$. This trend disappeared when microcarcinomas were excluded. For tumors more than $10 \mathrm{~mm}$ a trend was noted of an association between tumor size and the invasion of thyroid parenchyma and extrathyroidal invasion in all types of hyperthyroid patients, though this failed to reach statistical significance $\left(x^{2}=8.2, P=0.06\right)$; however, such an association was significant for patients with multinodular goiter $\left(x^{2}=7.4\right.$, $P=0.045)$. Nineteen out of 54 papillary carcinomas were multifocal. There was no significant difference in incidence of multifocality between the different types of hyperthyroidism $\left(x^{2}=0.861, P=0.66\right)$.

\section{Follow-up}

The median duration of follow-up was 54 months (range 14-205 months). All patients were followed up at six monthly intervals with clinical examination and high resolution neck ultrasonography. Thyroid stimulating hormone, serum thyroid hormones and thyroglobulin were measured annually. A patient was considered to be free of disease if all of the above assessments were negative including undetectable serum thyroglobulin after levothyroxine withdrawal and a negative whole body scan. At 18 months after the initial treatment, two patients (one with a history of solitary autonomous adenoma and one with toxic multinodular goiter) received additional therapy with 200 and $150 \mathrm{mCi}$ of ${ }^{131} \mathrm{I}$ to treat residual local disease. Two patients with solitary autonomous adenoma represented, one with bone metastases and multiple s.c. nodular metastases in the neck 2 years after thyroidectomy, and the other with cervical lymph node recurrence 10 years and lung metastases 12 years after diagnosis respectively. The first of these cases had a $6 \mathrm{~cm}$ follicular thyroid cancer located inside the

Table 2 Staging and outcome in patients with hyperthyroidism and thyroid cancer $>10 \mathrm{~mm}$.

\begin{tabular}{|c|c|c|c|}
\hline \multirow[b]{2}{*}{$n=21$} & \multicolumn{3}{|c|}{ Type of hyperthyroidism } \\
\hline & $\begin{array}{l}\text { Solitary autonomous adenoma } \\
\text { (cancer within the hot nodule) }\end{array}$ & Graves' disease & Toxic multinodular goiter \\
\hline Mean age \pm S.D. (years) & $55.33 \pm 14.29$ & $41.57 \pm 16.96$ & $60.63 \pm 8.16$ \\
\hline Cancer incidentally found after thyroidectomy & 3 & 4 & 4 \\
\hline Preoperatively suspicious cancer & 3 & 3 & 4 \\
\hline \multicolumn{4}{|l|}{ Stage at presentation } \\
\hline I & 2 & 1 & 2 \\
\hline II & 2 & 3 & 4 \\
\hline III & 1 & 3 & 1 \\
\hline IVA & 1 & & 1 \\
\hline Tumor size $\geq 10 \mathrm{~mm}$ & $6(35.3 \%)$ & $7(30.8 \%)$ & $8(29.6 \%)$ \\
\hline \multicolumn{4}{|l|}{ Histology } \\
\hline Papillary (including follicular variant) & 4 & 6 & 6 \\
\hline Follicular & 2 & 1 & - \\
\hline \multicolumn{4}{|l|}{ Duration of follow-up (months) } \\
\hline Median & 52 & 50 & 60 \\
\hline Range & $25-150$ & $14-168$ & 20-205 \\
\hline Disease specific mortality & Yes & No & No \\
\hline
\end{tabular}


hot nodule with thyroid capsular and vascular invasion at the time of diagnosis (Stage III). The second one had a $2.5 \mathrm{~cm}$ papillary thyroid cancer, columnar cell variant, also located inside the hot nodule, with extrathyroidal spread and multiple cervical lymph node metastases at the time of diagnosis (stage III). Both patients died due to metastatic thyroid cancer. Patients with medullary cancer were followed by neck ultrasound and by measuring serum calcitonin. During follow-up, one patient developed bone metastases and died from an unrelated cause 5 years after thyroidectomy.

\section{Discussion}

Thyroid carcinoma can be associated with various types of hyperthyroidism. Hyperthyroidism apparently does not 'protect' patients from thyroid cancer as it was believed years ago. Careful evaluation of hyperthyroid patients is always necessary to exclude the presence of associated malignancy and to determine the most appropriate therapeutic plan.

The size of malignant tumor was $\leq 10 \mathrm{~mm}$ in the majority of our patients. Although small in size, some of them presented lymph nodes metastases, invasion of thyroid parenchyma, extrathyroidal extension of the cancer, or had more than one foci with unilateral or bilateral location. Tumors more than $10 \mathrm{~mm}$ were found in $21 / 60(35 \%)$ of our patients. The incidence of tumors more than $10 \mathrm{~mm}$ in hyperthyroid patients has previously been reported to be between 27.3 and $65.4 \%$ (Table 3).

The reported prevalence of local invasion at diagnosis in patients with differentiated thyroid cancer ranges between 5 to $12 \%$ in large series (29-31). Our study has revealed a high prevalence of locally advanced thyroid cancer in patients with hyperthyroidism, including cases where no preoperative suspicion of cancer was present. The reasons for this are unclear and probably complex. It is possible that this observation may represent referral patterns to a tertiary centre, with low-risk coincidental cancers being managed locally. A change in the true incidence of thyroid cancer among patients with thyrotoxicosis is also a possibility, though no conclusions can be drawn from the available data. The true incidence of thyroid cancer in patients with autonomous adenomas may be underestimated when large doses of radioiodine are used to treat such cases (as opposed to surgery), which may be sufficient not only to cure the thyrotoxicosis but also the cancer. As hyperthyroidism is considered a benign disease, physicians may continue to treat patients (some of whom may happen to also harbor a thyroid cancer) with antithyroid drugs for years. Under such circumstances, the risk of thyroid cancer is probably underestimated and the decision about surgery is therefore delayed. Routine thyroid US scans and US-guided FNAB should be considered for complete evaluation of hyperthyroid patients, since this pathology frequently implies the development of thyroid nodules that are not always detectable on clinical or radionuclide examination. Surgery is mandatory when nodules with suspicious ultrasonographic features are found and if malignancy cannot be excluded with FNAC. Multinodularity of goiter should no longer be considered an indicator of probable benign disease. Since thyroid cancer may be present in hyperthyroid patients and may be invasive or metastatic, long-term therapy with antithyroid drugs should be carefully monitored, especially if a thyroid nodule is present. It is, therefore, preferable to avoid prolonged medical treatment and favor surgery over radioiodine for treating hyperthyroid patients, with suspicious nodules.

Our data show an aggressive behavior of autonomous solitary adenomas associated with thyroid cancer, compared with other causes of hyperthyroidism associated with cancer. In $58.8 \%$ of solitary autonomous adenomas associated with thyroid cancer, the tumor was located within the hot area observed on the isotope scan, including the two autonomous solitary adenomas that led to death. Thyroid cancer (either papillary or follicular) has been described in association with autonomously functioning adenomas (32, 33). Whether the two neoplasms (papillary thyroid cancer and follicular adenoma) arise independently of each other, or their coincidence is linked, is unknown.

The disease-specific mortality in the cohort of patients studied (with thyroid cancer and hyperthyroidism) was $3.3 \%$ over 4.5 years of mean follow-up. In comparison, 5 -year mortality of patients with thyroid cancer in Greece has been reported at 2\% (papillary) to $8 \%$

Table 3 Incidence of carcinomas $>10 \mathrm{~mm}$ in the different types of hyperthyroidism and carcinomas located in the hot nodules.

\begin{tabular}{lclll}
\hline & Patients & Type of hyperthyroidism & Tumor size $>\mathbf{1 0} \mathbf{~ m m}$ & Tumor inside the hot nodule \\
\hline Farbota (2) & 6 & Graves' disease & $3(50 \%)$ & $9 / 9$ \\
Belfiore (5) & 22 & Graves' disease, hot nodule & $9(40.9 \%)$ & $2 / 2$ \\
Ahuja (7) & 20 & All types & $13(65 \%)$ & $4 / 4$ \\
Vini (16) & 23 & All types & $11(47.8 \%)$ & $4 / 4$ \\
Ozaki (17) & 19 & Graves' disease & $8(42.1 \%)$ & $2 / 2$ \\
Cakir (25) & 26 & All types & $17(65.4 \%)$ & $7 / 7$ \\
Cerci (26) & 11 & Multinodular goiter & $3(27.3 \%)$ & $10 / 17$ \\
Taneri (27) & 10 & All types & $3(30 \%)$ & Not reported \\
Ikekubo (29) & 7 & Hot nodule & $12(19.7 \%)$ & $21(35 \%)$ \\
Chao (28) & 61 & Graves' disease & & \\
Our data & 60 & All types & &
\end{tabular}


(follicular) (29). It appears therefore that patients with thyroid cancer and thyrotoxicosis have as aggressive course to their cancer as those without thyrotoxicosis.

The data presented here raise questions as to how intensively patients presenting with hyperthyroidism should be investigated for the presence of coincidental thyroid cancer. Although there is insufficient evidence to base recommendations for any change in practice, clinicians managing patients with hyperthyroidism need to be aware of the possible increased risk of thyroid cancer in this patient group. In particular, the proposition that hot nodules are associated with exceedingly low probability of malignancy (6-8), needs to be re-evaluated in prospective studies.

\section{Declaration of interest}

The authors declare that there is no conflict of interest that could be perceived as prejudicing the impartiality of the research reported.

\section{Funding}

This research did not receive any specific grant from any funding agency in the public, commercial or not-for-profit sector.

\section{References}

1 Shapiro SJ, Friedman NB, Perzik SL \& Catz B. Incidence of thyroid carcinoma in Graves' disease. Cancer 197026 1261-1270.

2 Farbota LM, Calandra DB, Lawrence AM \& Paloyan R. Thyroid carcinoma in Graves' disease. Surgery 198598 1148-1152.

3 Kim WB, Han SM, Kim TY, Nam-Goong IS, Gong G, Lee HK, Hong SJ \& Shong YK. Ultrasonographic screening for detection of thyroid cancer in patients with Graves' disease. Clinical Endocrinology $2004 \mathbf{6 0} 719-725$.

4 Bolko P, Lacka K, Manuszewska E, Ruchala M, Majewski P \& Sowinski J. Is hyperthyroidism often present in patients with thyroid differentiated carcinoma? Polskie Archiwum Medycyny Wewnetrznej $2002 \mathbf{1 0 7}$ 555-559.

5 Belfiore A, Garofalo MR, Giuffrida D, Runello F, Filetti S, Fiumara A, Ippolito O \& Vigneri R. Increased aggressiveness of thyroid cancer in patients with Graves' disease. Journal of Clinical Endocrinology and Metabolism 199070 830-835.

6 Landgarten S \& Spencer RP. A study of the natural history of 'hot' nodule. Yale Journal of Biology and Medicine 197346 259-263.

7 Ahuja S \& Ernst H. Hyperthyroidism and thyroid carcinoma. Acta Endocrinologica $1991 \mathbf{1 2 4}$ 146-151.

8 Goretzki PE, Wahl RA, Branscheid D, Joseph K, Tsuchiya A \& Roher HD. Indication for operation of patients with autonomously functioning thyroid tissue in endemic goiter areas. World Journal of Surgery 19859 149-155.

9 Croom RD, Thomas CG Jr, Reddick RL \& Tawil MT. Autonomously functioning thyroid nodules in childhood and adolescence. Surgery 1987102 1101-1108.

10 Nagai GR, Pitts WC, Basso L, Cisco JA \& McDougall IR. Scintigraphic hot nodules and thyroid cancer. Clinical Nuclear Medicine 198712 123-127.

11 Sandler MP, Fellmeth B, Salhany KE \& Patton JA. Thyroid carcinoma masquerading as a solitary benign hyperfunctioning nodule. Clinical Nuclear Medicine 198813 410-415.

12 Hancock BW, Bing RF, Dirmikis SM, Munro DS \& Neal FE. Thyroid carcinoma and concurrent hyperthyroidism. Cancer 197739 298-302.

13 Wahl RA, Goretzki P, Meybier H, Nitschke J, Linder M \& Roher HD. Coexistence of hyperthyroidism and thyroid cancer. World Journal of Surgery 19826 385-390.
14 Mazzaferri EL, Young RL, Oertel JE, Kemmerer WT \& Page CP. Papillary thyroid carcinoma: the impact of therapy in 576 patients. Medicine 197756 171-196.

15 Rosler H, Wimpfheimer C, Ruchti Ch, Kinser J \& Teuscher J. Hyperthyreose bei maligner Struma. Nuklearmedizin 19846 293-300.

16 Vini L, Hyer S, Pratt B \& Harmer C. Good prognosis in thyroid cancer found incidentally at surgery for thyrotoxicosis. Postgraduate Medical Journal 199975 169-170.

17 Ozaki O, Ito K, Kobayashi K, Toshima K, Iwasaki H \& Yashiro T. Thyroid carcinoma in Graves' disease. World Journal of Surgery 199014 437-441.

18 Cappelli C, Braga M, Martino ED, Castellano M, Gandossi E, Agosti B, Cumetti D, Pirola I, Mattanza C, Cherubini L \& Rosei EA. Outcome of patients surgically treated for various forms of hyperthyroidism with differentiated thyroid cancer: experience at an endocrine centre in Italy. Surgery Today 200636 125-130.

19 Mazzaferri EL. Thyroid cancer and Graves' disease. Journal of Clinical Endocrinology and Metabolism 199070 826-829.

20 Edmonds CJ \& Tellez M. Hyperthyroidism and thyroid cancer. Clinical Endocrinology 198828 253-259.

21 Behar R, Arganini M, Wu TC, McCormick M, Straus FH, DeGroot LJ \& Kaplan EL. Grave's disease and thyroid cancer. Surgery $1986 \mathbf{1 0 0} 1121-1127$.

22 Wittekind C, Compton CC, Greene FL \& Sobin LH. TNM residual tumor classification revisited. Cancer $2002942511-2516$.

23 Rosai J \& Ackerman L. Surgical Pathology. Mosby edition, an affiliate of Elsevier, vol 2, (9th edn), pp 2970, 2004.

24 Pacini F, Schlumberger M, Harmer C, Berg GG, Cohen O, Duntas L, Jamar F, Jarzab B, Limbert E, Lind P, Reiners C, Sanchez Franco F, Smit J \& Wiersinga W. Post-surgical use of radioiodine (131I) in patients with papillary and follicular thyroid cancer and the issue of remnant ablation: a consensus report. European Journal of Endocrinology 2005153 651-659.

25 Cakir M, Arici C, Alacus H, Altunbas H, Balci MK \& Karayalcin V. Incidental thyroid carcinoma in thyrotoxic patients treated by surgery. Hormone Research 200767 96-99.

26 Cerci C, Cerci SS, Eroglu E, Dede M, Kapacuoglu N, Yildiz M \& Bulbul M. Thyroid cancer in toxic and non-toxic multinodular goiter. Journal of Postgraduate Medicine 200753 157-160.

27 Taneri F, Kurukahvecioglu O, Ege B, Yilmaz U, Tekin EH, Cifter C \& Onuk E. Clinical presentation and treatment of hyperthyroidism associated with thyroid cancer. Endocrine Regulations 200539 85-90.

28 Chao TC, Lin JD \& Chen MF. Surgical treatment of thyroid cancers with concurrent Graves disease. Annals of Surgical Oncology 2004 11 407-412.

29 Tzavara I, Vlassopoulou B, Alevizaki C, Koukoulis G, Tzanela M, Koumoussi P, Sotsiou F \& Thalassinos N. Differentiated thyroid cancer: a retrospective analysis of 832 cases from Greece. Clinical Endocrinology $199950643-654$.

30 Mazzaferri EL \& Jhiang SM. Long-term impact of initial surgical and medical therapy on papillary and follicular thyroid cancer. American Journal of Medicine 199497 418-428.

31 Emerick GT, Duh Q-Y, Siperstein AE, Burrow GN \& Clark OH. Diagnosis, treatment, and outcome of follicular thyroid carcinoma. Cancer 199372 3287-3295.

32 Mizukami Y, Michigishi T, Nonomura A, Yokoyama K, Noguchi M, Hashimoto T, Nakamura S \& Ishizaki T. Autonomously functioning (hot) nodule of the thyroid gland. A clinical and histopathologic study of 17 cases. American Journal of Clinical Pathology 1994 $10129-35$.

33 Ikekubo K, Hino M, Ito H, Otami M, Yamaguchi H, Saiki Y, Ui K, Habuchi Y, Ishihara T \& Mori T. Thyroid carcinoma in solitary hot thyroid lesions on Tc99m sodium pertechnetate scans. Annals of Nuclear Medicine 19893 31-36.

Received 2 September 2008

Accepted 2 September 2008 